\title{
Erupting Compound Odontome - A Case Report
}

\author{
Shreyas N. Shah'1, Falguni Patel ${ }^{2}$ \\ 1, 2 Department of Oral \& Maxillofacial Pathology and Microbiology, K.M. Shah Dental College and Hospital, \\ Sumandeep Vidyapeeth (Deemed to Be University), Vadodara, Gujarat, India.
}

\section{INTRODUCTION}

Odontomas are asymptomatic, benign odontogenic tumours comprised of dental tissue. Most of the cases usually get detected on routine radiographic evaluation. Odontoma can be classified according to morphology in two different variants, compound odontoma showing anatomic similarity or miniature version of the tooth and complex odontoma having irregular masses with different type of dental tissues. Early detection of such type of silent lesion is mandatory to rule out certain silent but aggressive pathologies. Here, we present a case of erupting compound odontoma of maxillary area in 15-year-old male patient.

Development of tooth is a result of complicated interaction between ectodermal and ecto mesenchymal tissue. Sometimes the remnants of such tissues are left behind in the jaw after development and eruption of tooth, which can become a source of development of odontogenic lesions later on. ${ }^{1}$ As revealed by World Health Organization (WHO), Odontogenic tumours can be classified in three different categories according to their histopathological form. ${ }^{2}$

1. Odontogenic tumours which develop from odontogenic epithelium without involvement of odontogenic ectomesenchyme,

2. Odontogenic tumours which develop from odontogenic epithelium with involvement of odontogenic ectomesenchyme, with or without formation of dental hard tissue and

3. Odontogenic tumours which develop from odontogenic ectomesenchyme with or without involvement of odontogenic epithelium. ${ }^{2}$

For such lesions "Odontoma” word was initially given by Paul Broca in 1866, who revealed the term as tumour occurred by the overgrowth of entire dental tissue. The growth of absolutely differentiated epithelial cells as functional ameloblast and mesenchymal cells as functional odontoblast can give rise to a different developmental anomaly coined as Odontomas. ${ }^{3}$ According to their behaviour and composition, odontomas can be considered as malformations or hamartomas rather than a true neoplasm.4,5,6

In 2005, World Health Organization (WHO) classified two variants of odontomas,

1. Compound odontomas, which typically appears as unilocular lesions containing multiple radiopaque, tiny tooth like structures commonly known as denticles; and

2. Complex odontomas, which is comprised of an irregular mass of soft and hard dental tissues.

Compound odontomas are about two times common as complex odontomas. $4,7,8,9$
Corresponding Author: Dr. Shreyas N. Shah,

Professor, Department of Oral

\& Maxillofacial Pathology

and Microbiology, K.M. Shah

Dental College and Hospital, Sumandeep

Vidyapeeth (Deemed to Be University),

Piparia - 391760, Vadodara,

Gujarat, India.

E-mail:vrajdent@gmail.com

DOI: $10.14260 / j e m d s / 2021 / 287$

How to Cite This Article:

Shah SN, Patel F. Erupting compound odontome - a case report. J Evolution Med Dent Sci 2021;10(18):1361-1364, DOI: 10.14260/jemds/2021/287

Submission 16-12-2020,

Peer Review 26-02-2021,

Acceptance 05-03-2021,

Published 03-05-2021.

Copyright (C) 2021 JEMDS. This is an open access article distributed under Creative Commons Attribution License [Attribution 4.0 International (CC BY 4.0)] 


\section{PRESENTATION OF CASE}

A 15-year-old male patient visited the Department of Oral Pathology and Microbiology with the chief complaint of missing teeth in anterior region of the upper jaw. No significant medical history and or history of maxillofacial trauma was seen in present case.

On clinical examination, a small tooth like structure was noticed in relation to 11 region intraorally and a diffuse swelling was seen in the labial vestibule, extending from 11 to 13 region, measuring $4 \mathrm{~cm} \times 2 \mathrm{~cm}$, [Figure 1A] As reported by the patient, the swelling had increased in size over past 2 weeks causing discomfort while eating and also hampering the aesthetics of the patient. There was no history of previous infection and no complain of pain. There was no sign of any extra oral and intraoral discharge. [Figure 2]
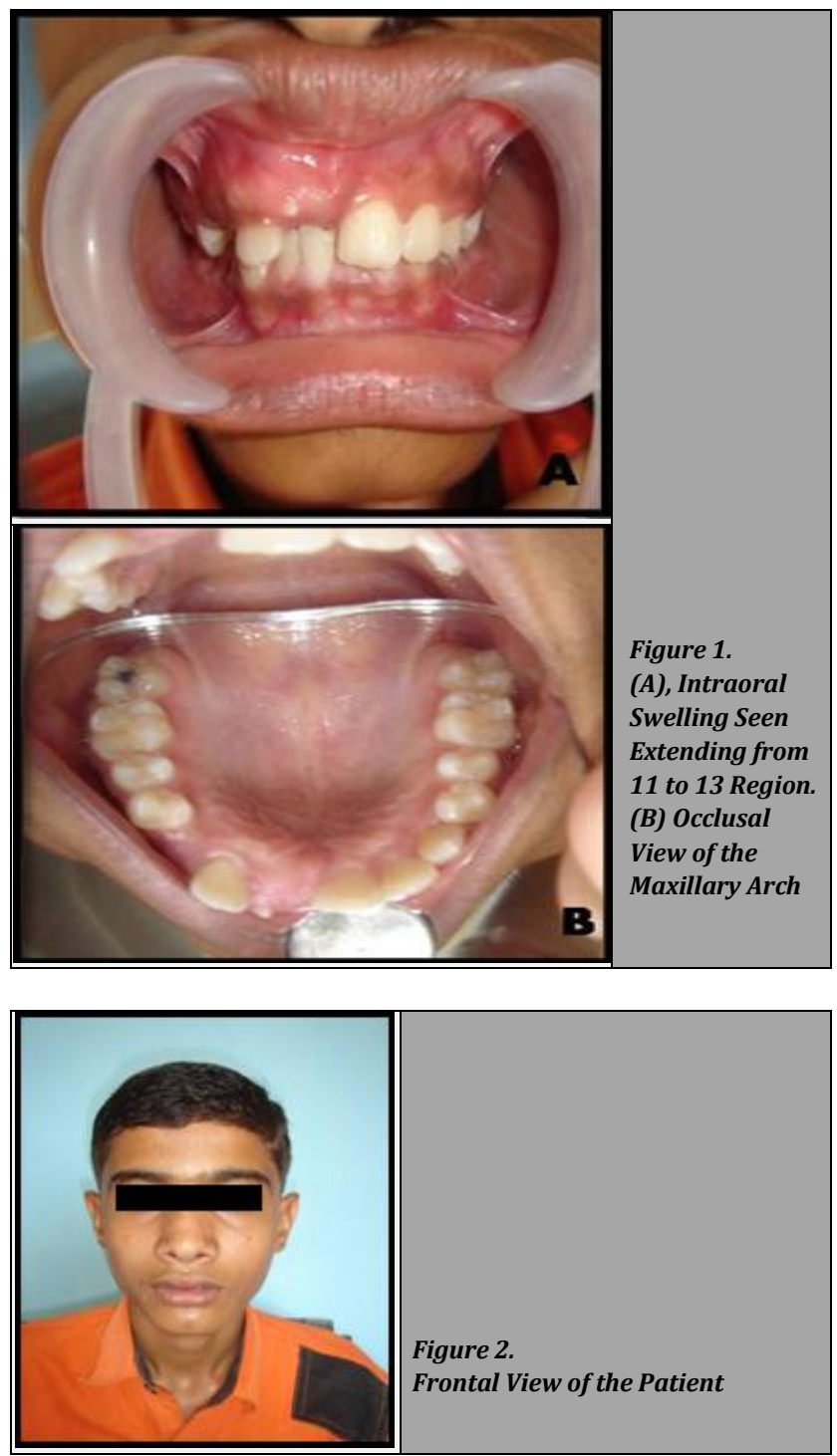

Figure 2.

Frontal View of the Patient

On inspection, the swelling was reddish pink in colour and on palpation it was bony hard and non-tender, non-fluctuant with diffuse borders. [Figure 1B] The Orthopantomograph (OPG) revealed a lesion with respect to 11 region showing irregular margins. Radiopacity was noticed with irregular calcified tissue structures present below an unerupted 11 and the radiopacity occupied the entire erupting area of 11 and also covered the adjacent tooth structures [Figure 3].

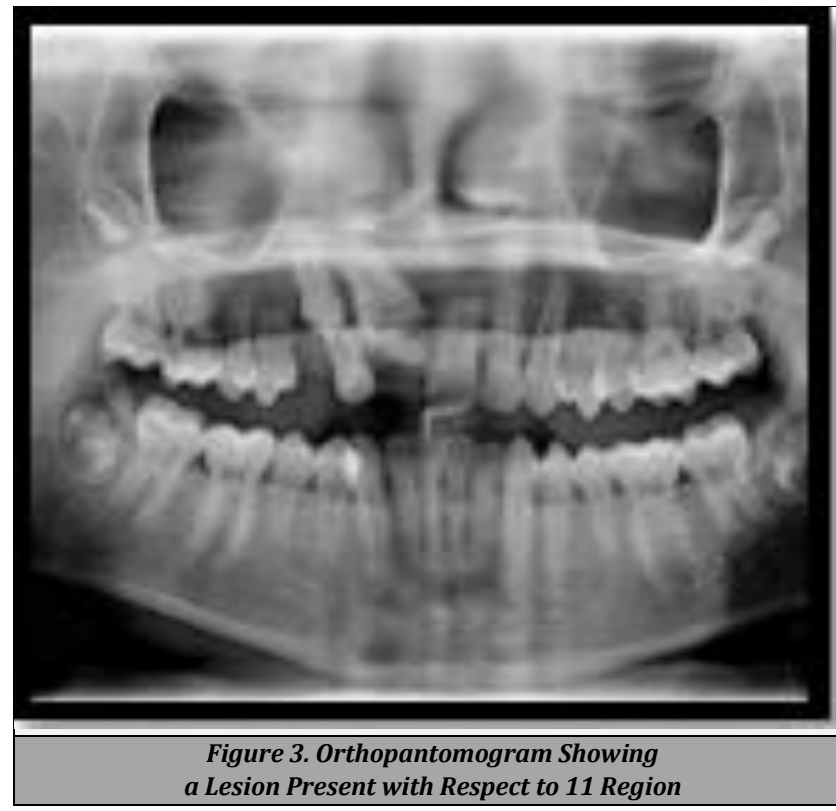

CLINICAL DIAGNOSIS

Odontoma.

\section{DIFFERENTIAL DIAGNOSIS}

Compound odontoma, complex odontoma and ameloblastic fibro-odontoma.

\section{DISCUSSION OF MANAGEMENT}

The lesion was enucleated under local anaesthesia, the enucleated calcified tooth like specimens were sent for histopathological examination.

\section{PATHOLOGICAL DISCUSSION}

\section{Gross Feature}

3 - 4 small calcified hard tissue specimens were received [Figure 4]. On examination the specimens resembled like a miniature version of tooth.

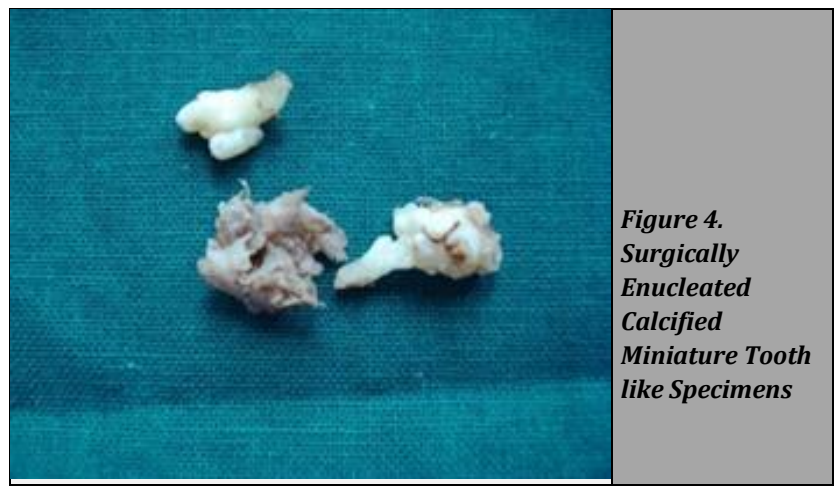




\section{Histopathological Findings}

Haematoxylin and eosine stained decalcified section of tooth like specimen showed irregularly arranged dental hard tissue resembling the tubular dentine with centrally placed fibrocellular connective tissue stroma [Figure 5A and B].

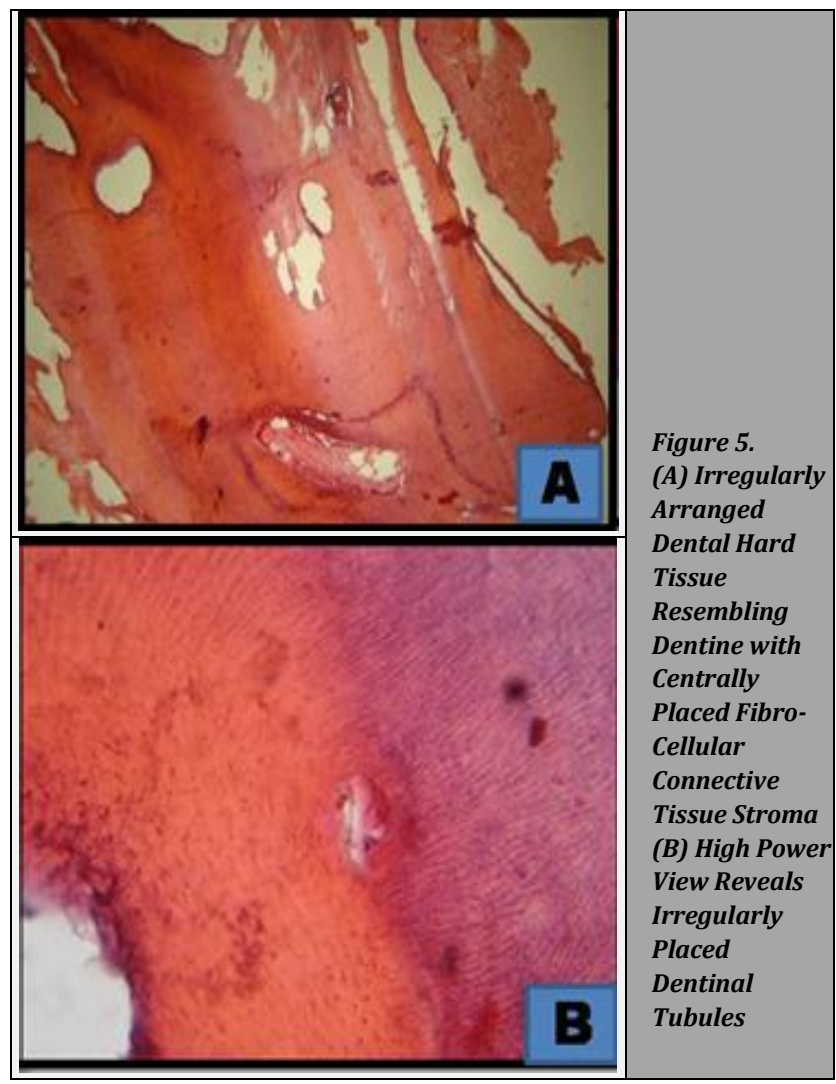

DISCUSSION

Odontomas are usually asymptomatic and are diagnosed on radiographs on routine examination. However, sometimes they may achieve large enough size to cause swelling in the jaw. An impacted or over retained deciduous tooth may serve as a clinical feature which indicates the occurrence of an odontoma. ${ }^{19,20}$ The preferred treatment for such lesions is surgical removal. ${ }^{20}$ It is important to take care not to damage adjacent teeth and permanent tooth germs in children at the time of surgical removal. Follow-up evaluation is necessary for tracking further development of permanent dentition at the surgically treated site. Even though the judgement of odontomas, in many cases, can be tentatively made with the help of radiographic interpretation, a histopathological evaluation of excised lesion is must to rule out other pathologies and also to confirm the diagnosis. ${ }^{21}$

The term "odontome," was initially used by Broca in 1866. He identified the lesion as a tumour which occurred due to overgrowth of entire dental tissue. ${ }^{10}$ The given term was extended with time which contains many other odontogenic tumours or cysts. Thoma and Goldman further precise the term "odontoma" as tumours which were comprised of welldistinguished tooth structure in their paper. ${ }^{11}$ Whereas, Shafer and Gorlin defined odontoma as a tumour which was established and distinguished sufficiently to harvest enamel and dentin structure. ${ }^{12,13}$

Odontoma is the commonest odontogenic tumour found in maxilla. Compound odontoma usually seen in relation to the upper incisors and canine areas with the second most common sites as antero and posteroinferior regions. Complex odontomas are generally noticed in the second and third molar areas of mandible. ${ }^{14}$

In present case, the compound odontoma was found in the region of upper right incisor. Children and adolescents show increased prevalence of such tumours compared to older individuals. Such type of lesions are usually diagnosed with the help of their unique radiographic appearance in the age group of 11 - 30 year. ${ }^{14}$

Odontomas show inherited pattern through a mutation in gene or interference in genetic activity, probably in postnatal period, within genetic control system of tooth development. It is seen that in humans, the lamina between the tooth germ has tendency to fragment into clumps of cells. If the remnants of disintegrated lamina are left behind, it can serve as an important part of the etiopathogenesis of complex and compound odontomas and may give rise to either of the two rather than development of a tooth. ${ }^{15}$ Being slow growing and often non-aggressive in nature, Odontomas are accidentally seen in radiographs in most of the cases. It occurs in the age group of 11 - 30 year with the mean age of 14 years at the time of diagnosis. ${ }^{16}$

Odontomas are frequently asymptomatic by nature. Usually, patients come with the chief complain of non-erupted permanent tooth, pain over retained deciduous tooth, displacement of tooth and expansion of cortical bone which serves as probable clinical indicators of occurrence of odontoma in that region. Whenever odontoma erupts in the oral cavity, it leads to swelling and pain and as a result of it, malocclusion occurs. There are evidences of its outcome in very young age as well as in older age.$^{7}$ In present case the odontoma was associated with unerupted.11 In the case of complex odontoma, there is presence of less well-ordered development of dental tissues which infrequently shows tooth or tooth like structures. ${ }^{14}$ Clinical interpretation alone cannot help in differentiating compound and complex odontoma because usually the odontoma lie within the bony structure and doesn't reveal any external signs like bone expansion.

Very rarely, we can see the eruption of odontomas in oral cavity. And also, it can be interpreted clinically and manually but their surface appearances are quite similar and hence only from the clinical point of view, identifying them as compound or complex is a difficult task. ${ }^{17}$ The complex odontoma shows a disorganized histopathological pattern of all dental tissues as though broad histodifferentiation has happened. There is always presence of a connective tissue capsule around the odontoma. ${ }^{18}$ The histopathological findings of present case revealed the features of compound odontoma.

\section{FINAL DIAGNOSIS}

Compound odontoma. 
Financial or other competing interests: None.

Disclosure forms provided by the authors are available with the full text of this article at jemds.com.

\section{REFERENCES}

[1] Melrose RJ. Benign epithelial odontogenic tumors. Semin Diagn Pathol 1999;16(4):271-87.

[2] Kramer IRH, Pindborg JJ, Shear M. Histological typing of odontogenic tumours. $2^{\text {nd }}$ edn. Berlin: Springer-Verlag 1992.

[3] Patil S, Rahman F, Tipu SR, et al. Odontomas: review of literature and report of case. Oral and Maxillofacial Pathology Journal 2012;3(1):224-7.

[4] Baldawa RS, Khante KC, Kalburge JV, et al. Orthodontic management of an impacted maxillary incisor due to odontoma. Contemp Clin Dent 2011;2(1):37-40.

[5] Yadav M, Godge P, Meghana SM, et al. Compound odontoma. Contemp Clin Dent 2012;3(Suppl 1):S13-5.

[6] Cawson R, Binnie W, Speight P, et al. Luca's pathology of tumors of the oral tissues. $5^{\text {th }}$ edn. London: Churchill Livingstone 1998: p. 83-5.

[7] Vengal M, Arora H, Ghosh S, et al. Large erupting complex odontoma: a case report. J Can Dent Assoc 2007;73(2):169-73.

[8] Serra-Serra G, Berini-Aytés L, Gay-Escoda C. Erupted odontomas: a report of three cases and review of the literature. Med Oral Patol Oral Cir Bucal 2009;14(6):E299-303.

[9] Morgan PR. Odontogenic tumors: a review. Periodontol 2000;57(1):160-76.
[10] Broca P. Traitev des tumeurs. Vol. 1. Paris: P. Asselin Books 1866: p. 350.

[11] Thoma KH, Goldman HM. Odontogenic tumors: a classification based on observations of the epithelial, mesenchymal and mixed varieties. Am J Pathol 1946;22(3):433-71.

[12] Shafer WG, Hine MK, Levy BM. Cysts and tumors of odontogenic origin. In: Textbook of Oral Pathology. 4th edn. Philadelphia, PA: WB Saunders 1983: p. 258.

[13] Gorlin RJ, Chaudhry AP, Pindborg JJ. Odontogenic tumors. Classification, histopathology and clinical behavior in man and domesticated animals. Cancer 1961;14:73-101.

[14] Budnick SD. Compound and complex odontomas. Oral Surg Oral Med Oral Pathol 1976;42(4):501-6.

[15] Hitchin AD. The aetiology of the calcified composite odontomes. Br Dent J 1971;130(11):475-82.

[16] Neville BW, Damm DD, Allen CM, et al. Odontogenic cysts and tumors. In: Neville BW, Damm DD, Allen CM, et al. eds. Oral and Maxillofacial Pathology. $2^{\text {nd }}$ edn. Philadelphia: WB Saunders 2002: p. 633-42.

[17] Kaneko M, Fukuda M, Sano T, et al. Microradiographic and microscopic investigation of a rare case of complex odontoma. Oral Surg Oral Med Oral Pathol Oral Radiol Endod 1998;86(1):131-4.

[18] Kumar BP, Nikhila K, Srinivas G, et al. Complex odontomaa case report. Indian J Dent Adv 2019;11(3):112-6.

[19] Nelson BL, Thompson LD. Compound odontoma. Head Neck Pathol 2010;4(4):290-1.

[20] An SY, An CH, Choi KS. Odontoma: a retrospective study of 73 cases. Imaging Sci Dent 2012;42(2):77-81.

[21] Iatrous I, Vardas E, Theologie-Lygidakis N, et al. A retrospective analysis of the characteristics, treatment and follow-up of 26 odontomas in Greek children. J Oral Sci 2010;52(3):439-47 